\title{
OBSERVANDO OS MOVIMENTOS RETÓRICOS NO ARTIGO ACADÊMICO NA ÁREA DA MULTIMODALIDADE ${ }^{1}$
}

Aluizio Lendl (UERN)

Resumo: O presente estudo tem como objetivo descrever e interpretar as unidades retóricas que compõem a área disciplinar da Multimodalidade. Trata-se de uma pesquisa cuja natureza é exploratório-descritiva. 0 corpus foi composto por quatro artigos da área de Multimodalidade, publicados em língua portuguesa em periódicos brasileiros indexados no banco de dados WebQualis da CAPES. Fundamentamo-nos nas perspectivas teórico-metodológicas de Swales (1990) e Motta-Roth; Hendges (2010) no que diz respeito ao estudo das unidades retóricas. O conceito de cultura disciplinar está filiado a Hyland (2000). No que concerne às unidades retóricas dos artigos, na seção de introdução, não encontramos indícios de revisão da literatura, embora sejam apresentadas referências das principais obras. Na seção de metodologia, as informações são construídas de forma incompleta. Na unidade dos resultados, são apresentados os principais achados do estudo. Por fim, evidenciamos que os artigos acadêmicos da cultura disciplinar delimitada são construídos de forma diversas, sem obedecer normas ou práticas investigativas disciplinares. Esperamos que nosso estudo possa contribuir com os estudos retóricos em artigos acadêmicos da área da Multimodalidade e ressaltamos a necessidade de estudos que tomem essas unidades retóricas como foco.

Palavras-chave: Descrição retórica; Cultura disciplinar; Artigo acadêmico; Multimodalidade.

Abstract: The present study aims to describe and interpret as rhetorical units that make up the disciplinary area of Multimodality. It is a research of nature is exploratory-descriptive. The corpus is composed of four articles from the Multimodality area, published in the Portuguese language in Brazilian journals indexed without CAPES WebQualis database. We base ourselves on the theoretical-methodological perspectives of Swales (1990) and Motta-Roth; Hendges (2010) with

1 Título do artigo em inglês: "OBSERVING THE RETROIC MOVEMENTS IN THE ACADEMIC ARTICLE IN THE MULTIMODALITY AREA" 
regard to the study of rhetorical units. The concept of disciplinary discipline is affiliated with Hyland (2000). Regarding the rhetorical units of the articles, in the introduction section, we find no evidence of literature review, in addition to references of the main works. In the methodology section, how information is constructed incompletely. In the unit of results, the main findings of the study are presented. Finally, we show that the articles are academic of the delimited disciplinary culture are constructed of diverse form, without obeying disciplinary norms or investigative practices. We hope that our study can contribute to rhetorical studies in academic articles in the area of Multimodality and we emphasize the need for studies that take these rhetorical units as a focus.

Keywords: Rhetorical description; Disciplinary culture; Academic article; Multimodality

\section{INTRODUÇÃO}

As pesquisas que envolvem os gêneros acadêmicos têm avançado nosúltimosanos, configurando uma área promissora dentro dos estudos dos gêneros textuais/discursivos. Muitos são os gêneros que circulam na universidade, dentre eles o resumo, a resenha, o projeto de pesquisa, o artigo acadêmico, dentre outros. Motta-Roth e Hendges (2010) explicam que o artigo acadêmico é um gênero que serve como uma via de comunicação entre pesquisadores, profissionais, professores e alunos de graduação e pós-graduação.

Por sua vez, Swales (1990) configura o gênero artigo acadêmico como uma classe de eventos comunicativos, cujos propósitos comunicativos são compartilhados pelos participantes de uma comunidade discursiva. Hyland (2000) 
reflete sobre o conceito de comunidades discursivas. Para o autor as culturas disciplinares são construídas e formam heterogêneas práticas discursivas que permitem que os sujeitos construam novas práticas. As disciplinas possuem peculiaridades que as distinguem e são entendidas pelas terminologias, normas e objetivos específicos de cada área.

Muitas pesquisas já foram realizadas em busca de compreender a validade das unidades retóricas de artigos acadêmicos. Como é o caso do trabalho de Pacheco (2016), que estudou o artigo de opinião na cultura disciplinar da nutrição; o trabalho de Bernadino (2007), que observou o metadiscurso interpessoal no artigo acadêmico; e o trabalho de Costa (2015), que realizou uma descrição sociorretórica em artigos experimentais. Nosso trabalho, por sua vez, busca contribuir no que se refere às configurações das unidades retóricas de artigos da área de Linguística, especificamente da área da Multimodalidade.

Embora Swales (1990) não estabeleça um modelo para descrição de todas as unidades retóricas de artigos, Lim (2006, Apud MOTTA-ROTH; HENDGES, 2010) traz um modelo proveniente da área da administração, o qual também tomaremos como base para nossas análises.

Nesse entendimento, questionamos como artigos acadêmicos da área da multimodalidade constroem 
suas seções e como as unidades retóricas são estruturadas? Como os sujeitos produzem e organizam as unidades retóricas de artigos acadêmicos? Com base nesses questionamentos, procuramos dar continuidade às discussões teóricas acerca das unidades retóricas de artigos acadêmicos.

Considerando que a circulação de artigos acadêmicos é uma forma de manter uma determinada comunidade disciplinar, nosso objetivo é descrever e interpretar as unidades retóricas que compõem a área disciplinar da Multimodalidade. Esperamos, portanto, que nosso estudo possa contribuir com futuras pesquisas.

Por fim, apresentamos a organização retórica do nosso artigo, construído a partir da Fundamentação Teórica, seguido da Metodologia e, por último, os resultados.

\section{FUNDAMENTAÇÃO TEÓRICA}

Nesta seção lançaremos conceitos acerca da ideia de cultura disciplinar (HYLAND, 2000) e das unidades retóricas de artigos de opinião (SWALES, 1990, 2004; MOTTA-ROTH; HENDGES, 2010). A fim de que esses estudos possam corroborar com a investigação de quatro artigos selecionados. Nosso propósito, portanto, não é discorrer incansavelmente a teoria, mas lançar pontos de relevância sobre a literatura escolhida. 
Desse modo, cabe mencionar que o estudo dos gêneros não é algo novo, sobretudo quando se trata dos gêneros acadêmicos. É inconteste o fato de que as múltiplas atividades humanas se realizam a partir de gêneros. Os homens atuam em esferas de atividades humanas, formais ou informais, tais como a escola, a igreja, no trabalho, no bairro ou em qualquer outra esfera de atividade, refletindo suas especificidades e suas finalidades.

Na universidade, por exemplo, muitos são os textos que circulam, tornando a comunicação viável a partir dos gêneros que cada espaço arquiteta. São relatório, resumo, frequência, fichamento, artigo acadêmico e uma infinidade de gêneros. Tendo consciência dessa heterogeneidade, trataremos especificamente dos artigos acadêmicos que circulam em uma área disciplinar.

O estudo acerca do artigo ganhou força a partir da abordagem sociorretórica, sob a ótica do Genre analysis (1990) e Research genres (2004) de Swales. Para o autor, nem todos os artigos se constituem de forma similar, ele explica que há diferenças entre artigos teóricos e artigos de revisão. Os teóricos propõem uma teoria para resolver alguma situação na área do conhecimento. Os de revisão, por outro lado, descrevem a situação atual, trazem uma 
visão histórica. Corroborando Swales, Motta-Roth e Hendges (2010, p.67) também ressaltam que há "tipos diferentes de artigos acadêmicos".

Para Hyland (2000) o objetivo do artigo acadêmico é estabelecer a produção científica de uma comunidade disciplinar, reconhecer as produções anteriores de um determinado discurso disciplinar e oferecer garantias acerca das questões construídas nos artigos e habilidades de negociação entre pares. Nesse sentido, Hyland destaca que é através dos artigos que os pesquisadores constroem o conhecimento da área disciplinar construindo a confiabilidade no assunto, construindo e mantendo sua autoridade cultural. Isto é, os textos produzidos incorporam as negociações sociais da área disciplinar.

O artigo acadêmico, para Hyland (2000), circula em uma comunidade disciplinar: acadêmica, e constitui o lugar onde essa cultura é construída. Sustentando que "o discurso é constituído socialmente ao invés de ser simplesmente compartilhado socialmente; escrita não é apenas um outro aspecto do que ocorre nas disciplinas, ela é vista como produção a delas" (HYLAND, 2000, p.3)²

O conhecimento acadêmico é produzido em uma área disciplinar e é constituído de elementos implícitos

2 (...) discourse is socially constitutive rather than simply socially shaped; writing is not just another aspect of what goes on in the disciplines, it is seen as producing them. 
e subjetivados pelas relações de poder, construído a partir de posições políticas, conhecimentos cultural e histórico, as regras e os objetos da pesquisa de determinada cultura disciplinar.

Swales (1990) descreve a caracterização retórica do artigo acadêmico. Para ele, as unidades básicas são Introdução, Métodos, Resultados e Discussão. Consoante a essa concepção, Motta-Roth e Hendges (2010) estudaram exatamente essa construção, mostrando as unidades retóricas de cada uma das seções indicadas.

As autoras propõem que a introdução do artigo seja construída/analisada a partir do modelo CARS (SWALES, 1990), cuja introdução do artigo acadêmico é composta por três movimentos básicos. Neste trabalho, usaremos o modelo CARS para examinar os artigos selecionados. Para entender a Revisão da Literatura dos artigos, seguiremos dois modelos: o primeiro é proposto de Motta-Roth e Hendges (1996, p.68) e o segundo por Figueiredo-Gomes (2017). Para Metodologia, seguiremos o modelo proposto por Lim (2006, Apud MottaRoth; Hendges, 2010). Para a unidade retórica de análise e discussão dos resultados, seguiremos a proposta de MottaRoth e Hendges (2010, p.128). Por fim, o modelo da seção de conclusão de artigo de Motta-Roth e Hendges (2010, p.131).

Embora muitos estudiosos se dediquem ao exercício da pesquisa de unidades retóricas de artigos acadêmicos, 
indicamos a necessidade de estudos que se dediquem a áreas disciplinares específicas, a fim de identificar como sujeitos de determinada área constroem o conhecimento. Ressaltamos, ainda, a necessidade de pesquisas que envolvam os artigos da área disciplinar da multimodalidade.

Entendida nossa base de sustentação teórica, na próxima seção faremos a exposição da metodologia dessa pesquisa.

\section{METODOLOGIA}

Este trabalho configura-se como uma pesquisa de caráter exploratório-descritivo, e procura descrever quantitativa e qualitativamente o comportamento retórico de artigos acadêmicos experimentais na cultura disciplinar da área da Multimodalidade, com vistas à recorrência dos movimentos e passos retóricos que caracterizam o gênero artigo.

O corpus dessa pesquisa são exemplares de artigos publicados em periódicos indexados pela CAPES (Coordenação de Aperfeiçoamento de Pessoal de Nível Superior). Os exemplares foram coletados dos periódicos no mês de outubro do ano de 2017. Construímos o corpus a partir de quatro (04) artigos acadêmicos experimentais da cultura disciplinar da área da Multimodalidade, os exemplares foram publicados entre 2011 e 2016 e são provenientes de três periódicos brasileiros. 
Quanto aos procedimentos de coleta e seleção do corpus, decidimos selecionar artigos fruto de pesquisas que tivessem como autores ou coautor pelo menos um doutor ou estudante de doutorado, ainda que os artigos tivessem no máximo dois autores e que tratassem especificamente de estudos da área da Multimodalidade.

No que diz respeito ao percurso metodológico para a descrição dos artigos, encontramos fundamento no modelo CARS de Swales (1990), nos modelos propostos por MottaRoth e Hendges (1996, p.68) e por Figueiredo-Gomes (2017), acerca da Revisão da Literatura, no modelo de Lim (2006, Apud de Motta-Roth e Hendges, 2010), para o estudo da unidade Metodológica. Para a unidade retórica de Análise e Discussão e Conclusão, o modelo de Motta-Roth e Hendges (2010).

Após expor nossos procedimentos metodológicos, passaremos a discutir as unidades retóricas presentes nas seções dos artigos selecionados.

\section{RESULTADOS}

Nesta seção, apresentaremos os resultados do nosso estudo. Propomo-nos fazer uma descrição qualitativa e quantitativa dos quatro artigos selecionados dos periódicos indexados pela CAPES. Os artigos são frutos de pesquisas oriundas da área disciplinar da Multimodalidade. 
Decidimos dividir essa seção em cinco subseções, as quais tratam, respectivamente, da Introdução, Revisão da Literatura, Método, Resultados e Conclusão.

\subsection{Discussão acerca da introdução}

A introdução do primeiro artigo analisado, de Duarte e Pontes (2013), está organizada em três parágrafos sintéticos. Observando o modelo CARS de Swales (1990), notamos que o artigo não estabelece o território, deixando de explorar a importância da pesquisa, as generalizações sobre o assunto e a revisão da literatura. Quanto ao estabelecimento do nicho, também ficou claro que os autores não deram a devida atenção.

Por outro lado, no que diz respeito à ocupação do nicho, o trabalho é delineado a partir do seguinte trecho: "Este artigo tem por objetivo realizar uma análise de páginas referentes a um dicionário eletrônico on-line a partir da metafunção composicional" (DUARTE; PONTES, 2013). Entretanto não apresenta a pesquisa, tampouco os seus principais resultados.

No último parágrafo, os autores metaenunciam a organização do artigo:

\section{Excerto 01:}

Nosso trabalho será dividido da seguinte maneira: primeiramente, discutiremos a metafunção composicional e apresentaremos as classificações que a ela se referem; depois, discorreremos sobre dicionários e também sobre a seleção do material em análise, para, em seguida, analisarmos as amostras escolhidas de acordo com as classificações apresentadas. Por último, nas considerações finais, teceremos algumas conclusões a respeito do que foi analisado. (DUARTE; PONTES, 2013) 
Como vimos no excerto, os autores apresentam a organização do trabalho, seguindo fielmente o estabelecido no modelo CARS (Swales, 1990). Um movimento em destaque, não citado na proposta de Swales, que aparece em três dos quatro artigos escolhidos é a indicação do referencial teórico que irá nortear a pesquisa. Normalmente, nos artigos selecionados, os autores dos artigos citam o aparato teórico, mas não discutem a teoria e não fazem contra-argumentos, conforme podemos observar no quadro a seguir:

\begin{tabular}{|c|c|}
\hline \multicolumn{2}{|c|}{ Novo movimento: Indicar referencial teórico. } \\
\hline $\begin{array}{l}\text { DUARTE, E.; PONTES, A. (2013.2). “A metafunção } \\
\text { composicional nas páginas do dicionário on-line } \\
\text { Merriam-Webster". Revista E-scrita. V. 4, 51-68. }\end{array}$ & $\begin{array}{l}\text { (...) Gramática do Design Visual de Kress e } \\
\text { van Leeuwen (2006), além de textos de au- } \\
\text { tores como Damim (2005), Pontes (2009) e } \\
\text { Torruella (2002). }\end{array}$ \\
\hline $\begin{array}{l}\text { FECHINE, L. A. R.; PONTES, Antônio Luciano } \\
\text { (2011). "A construção verbal e visual dos verbe- } \\
\text { tes de um dicionário monolíngue básico em lín- } \\
\text { gua inglesa". ReVEL, v. 9, n. } 17 \text {. }\end{array}$ & $\begin{array}{l}\text { (...) Gelpí e Castillo (2004) e Pontes (2009) } \\
\text { com relação ao verbete lexicográfico, as- } \\
\text { pectos da teoria da multimodalidade de } \\
\text { Kress e van Leeuwen (2006) para análise } \\
\text { dos recursos visuais e taxonomias discu- } \\
\text { tidas por Bosque (1982), Porto Dapena } \\
(2002),(\ldots)\end{array}$ \\
\hline $\begin{array}{l}\text { CARVALHO, S. A. (2016). "Interações imagem- } \\
\text { texto: uma análise de composições multimodais } \\
\text { instrucionais". RBLA, Belo Horizonte, v. 16, n. } 4 \text {, } \\
547-573 .\end{array}$ & AUSENTE \\
\hline $\begin{array}{l}\text { HERMONT, T. B. V. (2016). “Uma análise multi- } \\
\text { modal à luz do modelo GeM: homepage do Mi- } \\
\text { nistério do Meio Ambiente do Brasil”. RBLA, Belo } \\
\text { Horizonte, v. 16, n. 4, 709-743. }\end{array}$ & $\begin{array}{l}\text { A análise da página inicial do ministério fe- } \\
\text { deral por meio do modelo Gênero e Mul- } \\
\text { timodalidade (GeM) (BATEMAN, 2008) (...) }\end{array}$ \\
\hline
\end{tabular}

Quadro 01: Novo movimento retórico (Fonte: Desenvolvido a partir dos artigos selecionados)

$\mathrm{Na}$ introdução do segundo artigo, no de Fechine e Pontes (2011), o movimento retórico de estabelecer o território 
e estabelecer o nicho não são contemplados. Os autores desenvolvem a introdução do artigo em cinco parágrafos, cujo objetivo é analisar "a importância dos diferentes recursos multimodais para a localização de informações específicas no interior dos verbetes" (FECHINE; PONTES, 2011, p.02). A pesquisa também apresenta como o corpus é selecionado: "A seleção da macroestrutura é baseada em um corpus computadorizado denominado Bank of English" (FECHINE; PONTES, 2011, p.01). Por fim, Fechine e Pontes (2011, p.02) desenvolvem a seguinte finalização: “O trabalho está dividido em duas seções principais. Primeiramente, discorremos, de forma (...). Em seguida, baseados na teoria acima referida, analisamos cinco verbetes do dicionário".

No artigo de Carvalho (2016), a introdução parece ser a que oferece a maior quantidade de movimentos retóricos elencados por Swales (1990). Ela apresenta a importância da pesquisa, faz generalizações e revisa parcialmente a literatura. No primeiro ponto, ela recorre ao seguinte trecho: “É, portanto, de fundamental importância entender as relações entre a linguagem verbal e os outros modos não linguísticos de comunicação" (CARVALHO, 2016 p.549).

Tendo em vista a apresentação parcial da literatura abordada, Carvalho realiza contra-argumento a partir do 
sintagma nominal "Embora os autores (...)"3. Na sequência, a introdução não identifica as lacunas da referida abordagem teórica, tampouco explica se seu trabalho parte de alguma continuação de uma tradição de estudos da área ou se pretende refutar a abordagem.

Os objetivos também são bem delimitados e apresentados de forma clara, bem como a apresentação da pesquisa e seus interesses, como podemos observar no seguinte trecho: “(...) estamos especialmente interessadas em explorar as relações entre o texto escrito e as imagens estáticas no contexto de ensino de língua inglesa a distância" (CARVALHO, 2016, p.550).

Na sequência, buscamos no corpo da introdução indícios de possíveis resultados das pesquisas, contudo, nada foi evidenciado. No parágrafo final, Carvalho apresenta a esquematização das futuras seções do artigo.

O artigo de Hermont (2016), por sua vez, constrói a introdução em duas páginas, divididas em seis parágrafos e uma citação recuada. Nos movimentos retóricos empreendidos, o autor do artigo sobre o modelo GeM apresenta apenas três aspectos. Faz generalizações sobre o assunto e traz questionamentos, um diferencial entre os outros artigos: "Questionamos se os cidadãos brasileiros

3 É, portanto, de fundamental importância entender as relações entre a linguagem verbal e os outros modos não linguísticos de comunicação. (CARVALHO, 2016, p.459) 
têm a oportunidade de acessar as informações oficiais do ministério em questão de mais de um modo semiótico e se o portal eletrônico (...)" (HERMONT, 2016 p.711). Em seguida, observamos que Hermont apresenta o objetivo e finaliza o texto sem apresentar as partes do artigo.

\subsection{Discussão acerca da revisão da literatura}

Como vimos, na introdução dos artigos há apenas uma menção acerca da abordagem teórica. Nesse sentido, passaremos, nesta subseção, à compreensão de como a bibliografia é tomada no segmento revisão da literatura.

A revisão da literatura, invocada por Motta-Roth \& Hendges (2010 p.90), é uma forma de indicar, evidenciar, emprestar e demostrar a familiaridade com a produção de conhecimento da área. Percebemos que os autores dos artigos, em suma, não "situam a pesquisa" (Motta-Roth; Hendges, 2010, p.93), mas apresentam elementos do modelo de Figueiredo-Gomes (2017).

Duarte e Pontes (2013), como mencionado anteriormente, não apresentam nenhum elemento responsável por situar a pesquisa. Entretanto, apresentam de forma clara a orientação teórica da pesquisa ao destacar que ela toma a "Multimodalidade (Gramática do design visual) e o âmbito da Metalexicografia, ao estudo do dicionário." (DUARTE; PONTES, 2013, p.52). 
A menção das obras representativas não parece elemento retórico comum nos artigos. Apenas o artigo de Duarte e Pontes (2013) apresenta esse elemento, se bem que ele apresenta apenas uma obra, enquanto as demais teorias que sustentam o artigo não são mencionadas. Por outro lado, nos demais artigos, os principais representantes da teoria e a apresentação da teoria são elementos recorrentes, isto é, estes movimentos retóricos são parte integradora.

Evidenciamos que nenhum dos artigos destaca a indicação das lacunas do conhecimento objetivo. Sob a perspectiva do rigor terminológico, os autores apresentam conceitos com precisão terminológica, conforme mostramos no quadro a seguir:

\begin{tabular}{|l|l|l|l|}
\hline \multicolumn{5}{|c|}{ RIGOR TERMINOLÓGICO } \\
\hline $\begin{array}{l}\text { DUARTE; PONTES } \\
(2013)\end{array}$ & $\begin{array}{l}\text { FECHINE; } \\
(2011)\end{array}$ & PONTES & CARVALHO (2016) \\
\hline Sintagmas nominais & Sintagmas nominais & Sintagmas nominais & Sintagmas nominais \\
\hline $\begin{array}{l}\text { metafunção composi- } \\
\text { cional (...) }\end{array}$ & $\begin{array}{l}\text { enunciado lexicográfi- } \\
\text { co / palavra-entrada }\end{array}$ & $\begin{array}{l}\text { função representacio- } \\
\text { nal /função interativa } \\
\text { /função composicional }\end{array}$ & $\begin{array}{l}\text { Affordances / semióti- } \\
\text { ca social }\end{array}$ \\
\hline
\end{tabular}

Quadro 02: Terminologia (Fonte: Desenvolvido a partir dos artigos selecionados)

O quadro destacou alguns dos sintagmas nominais mais encontrados nos artigos, alertamos que outros termos são apresentados, mas em virtude do foco deste estudo, limitamo-nos em expor apenas os que compreendem de forma clara a relação entre teoria e objeto de estudo. 
Carvalho (2016) parece ser a única autora que apresenta quase que a maioria dos movimentos retóricos entre os dois modelos de base. Faz generalizações (As TI têm proporcionado um rápido desenvolvimento da educação a distância que, p.548) e contra-argumenta pesquisas prévias com a utilização do sintagma nominal "embora" (Embora os autores estivessem se referindo à linguagem verbal, eles reconhecem que sua visão de texto permite, p.549). Hermont (2016), por sua vez, apenas contra-argumenta a partir do sintagma verbal "discordamos" (Discordamos da ideia de que a linguagem, percebida como um conjunto de regras (...), p.714).

Constatamos na análise da literatura dos artigos que os movimentos retóricos desenvolvidos seguem formas variadas. Em geral, os trabalhos não apresentam os elementos de Motta-Roth; Hendges (2010, p.93), com exceção de dois artigos que apresentam um ou outro elemento, enquanto no esquema de Figueiredo-Gomes (2017) os artigos seguem o modelo de forma mais sistemática, apresentando uma média de $70 \%$, aproximadamente, do modelo preenchido.

Por fim, percebemos que a revisão da literatura necessita ser construída com a intenção de promover e situar os estudos da área. Sendo indispensável maior atenção aos elementos retóricos na literatura de cada artigo. Entendido isso, pensamos 
ser importante o desenvolvimento de pesquisas que tomem como foco essas unidades retóricas, a fim de constatar sua validade e evidenciar outros movimentos em processo de cristalização. Na sequência, buscaremos entender os passos metodológicos empreendidos nos artigos selecionados.

\subsection{Discussão acerca da metodologia}

A metodologia de um artigo é o momento no qual o produtor do artigo explicita o método de abordagem e o momento no qual o leitor pode conhecer e replicá-lo em sua pesquisa.

Seguindo o modelo de Lim (2006, Apud Motta-Roth; Hendges, 2010), os trabalhos de Duarte; Pontes (2013) e Fechine; Pontes (2011) não apresentam uma seção para metodologia, portanto, os dados foram coletados ora na introdução, ora na revisão da literatura, ora na análise dos dados. Embora tenhamos buscado em todas as partes do artigo as unidades retóricas, encontramos apenas o movimento de descrição do local da amostra:

\section{Excerto 02:}

O dicionário eletrônico Merriam-Webster, o qual, segundo o próprio site (www. merriam-webster.com), carrega uma tradição de mais de 150 anos nas obras impressas e, agora no meio digital, já atende cerca de 40 milhões de visitantes por dia (...) (DUARTE; PONTES, 2013, p.59) 


\section{Excerto 03:}

O Collins Cobuild Illustrated Basic Dictionary of American English (2010) é um dicionário monolíngue semasiológico especialmente desenvolvido para aprendizes em fase de transição entre a obra lexicográfica bilíngue e a monolíngue (FECHINE; PONTE, 2011, p.1)

Na descrição de Duarte e Pontes (2013) o elemento citado encontra-se na análise dos dados de seu artigo, enquanto na pesquisa de Fechine e Pontes (2011) fomos buscar na introdução o local da amostra.

Fechine e Pontes (2011) descreveram o tamanho/ dimensão da amostra/população, “(...) faremos uma análise da estrutura de cinco verbetes do dicionário em estudo" (FECHINE; PONTES, 2011, p.04) e Duarte e Pontes (2013) destacaram as vantagens de usar a amostra:

\section{Excerto 04:}

(...) a obra anteriormente citada foi escolhida principalmente devido ao fato de que a diversidade de dicionários eletrônicos on-line é significativa, contudo, não há um grande número de pesquisas desenvolvidas que tratem especificamente desse tipo de dicionário, diferente do modelo analógico impresso (...) (DUARTE; PONTES, 2013, p.59)

As demais unidades retóricas da metodologia não foram encontradas. Assim, os dois artigos não narram os passos da coleta dos dados, não delimitam os procedimentos para mensurar variáveis e não elucidam os procedimentos de análises dos dados.

Seguindo estruturação diferente, Hermont (2016) apresenta uma seção metodológica, esclarece que a sua 
pesquisa é de caráter qualitativo e quantitativo, alimentando seu texto com citações acerca dessa abordagem. Hermont descreve a amostra, o Portal do Ministério do Meio Ambiente do Brasil, e descreve as características da amostra, "o Ministério do Meio Ambiente do Brasil possui uma página inicial que pode ser caracterizada como mutável, ou seja, uma homepage que tem seu layout, cores (...)", entretanto esta informação aparece na análise dos dados. A variável seria, portanto, conforme nossas inferências, o framework do portal.

Seguindo o mesmo padrão de Hermont (2016), Carvalho (2016) também apresenta seção metodológica. Podemos afirmar que o trabalho de Carvalho é o que melhor apresenta os elementos metodológicos da pesquisa. A autora descreve - local da amostra, descreve a dimensão da amostra e descreve as características da amostra. Ela narra os passos da pesquisa:

Excerto 05:

primeiramente fizemos um levantamento das escolhas feitas pela professora e elaboradora da disciplina em relação aos recursos semióticos utilizados por ela no material didático. Depois, isolamos as composições multimodais instrucionais constituídas por imagens estáticas e todo o conteúdo verbal a elas relacionado presentes no material da disciplina. (CARVALHO, 2016, p.559)

Após narrar essa etapa, foi possível observar que Carvalho (2016) não justifica os procedimentos de coleta de 
dados utilizados. Por outro lado, delineia os procedimentos para mensurar as variáveis, definindo-as: "quatro lições, hospedadas em um ambiente virtual de aprendizagem. Cada lição é composta por quatro páginas da web, denominadas introdução (introduction), pré-tarefa (pre-task), tarefa (task) e pós-tarefa (post-task)" (CARVALHO, 2016, p.559).

As análises evidenciaram muitas divergências na composição das seções de metodologia, pois, dois artigos sequer apresentaram a seção, enquanto os outros dois apresentaram a seção dedicada à metodologia, mas não conseguiram contemplar todos os elementos. Nesse sentido, constatamos que as informações metodológicas são incompletas, deixam brechas na compreensão do processo de constituição dos dados da pesquisa, não oferecem fundamentação e justificativa para o uso dos procedimentos. Pensamos, portanto, ser imprescindível o desenvolvimento de mais trabalhos que foquem os movimentos retóricos das metodologias de artigos científicos.

Na subseção seguinte buscaremos enfocar a composição das unidades retóricas da seção de análise dos artigos selecionados.

\subsection{Discussão acerca dos resultados da pesquisa}

Decidimos organizar esta subseção em dois blocos. 0 primeiro trata-se da parte inicial das discussões, no que 
diz respeito à recapitulação das informações, declaração dos resultados e a explicação final dos resultados. No segundo, procuramos destacar a parte final do texto de discussão, relativo à avaliação da descoberta, comparação da descoberta com a literatura, generalização, resumo e conclusão.

Assim, apresentaremos a seguir a retórica no quadro 03:

\begin{tabular}{|c|c|c|c|c|}
\hline \multicolumn{5}{|c|}{ ORGANIZAÇÃO RETÓRICA DA SEÇÃO DE RESULTADOS E DISCUSSÃO } \\
\hline \multicolumn{5}{|c|}{ PARTE INICIAL } \\
\hline $\begin{array}{l}\text { Tipo de movi- } \\
\text { mento }\end{array}$ & $\begin{array}{l}\text { DUARTE; PONTES } \\
(2013)\end{array}$ & $\begin{array}{l}\text { FECHINE; PONTES } \\
(2011)\end{array}$ & CARVALHO (2016) & HERMONT (2016) \\
\hline $\begin{array}{l}\text { Recapitulação } \\
\text { de informação } \\
\text { metodológica }\end{array}$ & AUSENTE & $\begin{array}{l}\text { Parcialmente, apre- } \\
\text { sentando apenas } \\
\text { os verbetes que } \\
\text { serão analisados. }\end{array}$ & $\begin{array}{l}\text { Parcialmente, apre- } \\
\text { sentando apenas a } \\
\text { quantidade de au- } \\
\text { las que serão ana- } \\
\text { lisados. }\end{array}$ & AUSENTE \\
\hline $\begin{array}{l}\text { De cl a r ação } \\
\text { dos resulta- } \\
\text { dos }\end{array}$ & $\begin{array}{l}\text { Vemos que os par- } \\
\text { ticipantes internos } \\
\text { da imagem se en- } \\
\text { contram em (...) }\end{array}$ & $\begin{array}{l}\text { Percebemos o ca- } \\
\text { ráter simplista da } \\
\text { linguagem utiliza- } \\
\text { da na explicação } \\
\text { quando os autores } \\
\text { (...) }\end{array}$ & $\begin{array}{l}\text { Observa-se ainda } \\
\text { que as semioses } \\
\text { mais } \\
\text { comuns são entre } \\
\text { imagens estáticas e } \\
\text { texto verbal. (...) }\end{array}$ & $\begin{array}{l}\text { O que se nota é um } \\
\text { grau mais refinado } \\
\text { de unidades ainda } \\
\text { mais granuladas, } \\
\text { mas nem por isso } \\
\text { menos (...) }\end{array}$ \\
\hline $\begin{array}{l}\text { Explicação do } \\
\text { final in(espe- } \\
\text { rado) }\end{array}$ & $\begin{array}{l}\text { (...)bloco informati- } \\
\text { vo microestrutural } \\
\text { em relação aos de- } \\
\text { mais blocos apre- } \\
\text { senta coerência } \\
\text { interna em termos } \\
\text { da metafunção } \\
\text { composicional. }\end{array}$ & AUSENTE & $\begin{array}{l}\text { Não foi detectado } \\
\text { no uso dessa CMI } \\
\text { nenhuma relação } \\
\text { direta com o obje- } \\
\text { tivo da professora } \\
\text { de que os alunos } \\
\text { percebam a } \\
\text { estrutura das narra- } \\
\text { tivas. }\end{array}$ & $\begin{array}{l}\text { evidencia a ma- } \\
\text { neira pela qual o } \\
\text { documento se con- } \\
\text { solida em grandes } \\
\text { blocos de informa- } \\
\text { ção visual. É possí- } \\
\text { vel afirmar que } \\
\text { elementos visuais } \\
(\ldots)\end{array}$ \\
\hline
\end{tabular}

Quadro 03: Resultados parte 01 (Fonte: Desenvolvido a partir dos artigos selecionados) 
O quadro organizado mostra de forma clara que os resultados dos artigos não seguem de forma fiel o painel de avaliação proposto por Motta-Roth e Hendges (2010, p.128). As autoras explicam que esses movimentos são essenciais, pois, "a função do artigo de opinião é relatar RESULTADOS de uma pesquisa" (p.128 - grifo das autoras).

Observamos que a recapitulação das informações, quando feitas, são construídas de forma parcial, sem contemplar as informações necessárias. Nos quatro artigos, ainda, podemos observar que a declaração dos resultados foi construída explicitamente, podemos destacar que a maior parte da seção de resultados é composta por esse movimento retórico. Por fim, os autores explicitam o final (in)esperado, contudo, não é uma unidade retórica clara, sendo necessário buscá-los dissolvidos por entre outros movimentos retóricos.

A segunda parte da organização retórica, podemos observar no quadro 04 disposto a seguir: 


\section{ORGANIZAÇÃO RETÓRICA DA SEÇÃO DE RESULTADOS E DISCUSSÃO}

PARTE FINAL

\begin{tabular}{|c|c|c|c|c|}
\hline $\begin{array}{l}\text { Tipo de movi- } \\
\text { mento }\end{array}$ & $\begin{array}{l}\text { DUARTE; PON- } \\
\text { TES (2013) }\end{array}$ & $\begin{array}{l}\text { FECHINE; PON- } \\
\text { TES (2013) }\end{array}$ & $\begin{array}{l}\text { C A R V A L H O } \\
(2016)\end{array}$ & $\begin{array}{l}\text { C A R V A L H O } \\
(2016)\end{array}$ \\
\hline $\begin{array}{l}\text { Avaliação da } \\
\text { descoberta }\end{array}$ & AUSENTE & AUSENTE & AUSENTE & AUSENTE \\
\hline $\begin{array}{l}\text { Comparação da } \\
\text { descoberta com } \\
\text { a literatura }\end{array}$ & $\begin{array}{l}\text { Zonas do dado } \\
\text { (esquerda) e do } \\
\text { ideal (topo) no } \\
\text { todo imagéti- } \\
\text { co, o que cria, } \\
\text { conf. Kress e } \\
\text { van Leeuwen } \\
\text { (2006), um tipo } \\
\text { de hierarquia }\end{array}$ & $\begin{array}{l}\text { Marcas desta } \\
\text { natureza são } \\
\text { classificadas } \\
\text { como tecnole- } \\
\text { tais ou diatéc- } \\
\text { nicas } \\
\text { (PONTES, 2009: } \\
\text { 157). }\end{array}$ & $\begin{array}{l}\text { Não foi perce- } \\
\text { bida nenhuma } \\
\text { outra relação } \\
\text { entre o texto } \\
\text { e a imagem a } \\
\text { não ser a rela- } \\
\text { ção que Barthes } \\
\text { (1967) denomi- } \\
\text { nou de ilustra- } \\
\text { ção. }\end{array}$ & $\begin{array}{l}\text { Base do modelo } \\
\text { GeM, conforme } \\
\text { Bateman (2008) } \\
\text { salienta. Isso } \\
\text { ocorre, pois esta- } \\
\text { mos lidando com } \\
\text { a identificação } \\
\text { dos (...) }\end{array}$ \\
\hline Generalização & AUSENTE & AUSENTE & AUSENTE & AUSENTE \\
\hline Resumo & AUSENTE & AUSENTE & $\begin{array}{l}\text { O texto consti- } \\
\text { tui-se, portanto, } \\
\text { no principal ele- } \\
\text { mento } \\
\text { da CMI, a ima- } \\
\text { gem apenas } \\
\text { ilustra um de- } \\
\text { terminado as- } \\
\text { pecto deste }\end{array}$ & AUSENTE \\
\hline Conclusão & AUSENTE & $\begin{array}{l}\text { AUSENTE (ter- } \\
\text { mina com cita- } \\
\text { ção recuada) }\end{array}$ & $\begin{array}{l}\text { Vimos nesta } \\
\text { seção algumas } \\
\text { das formas atra- } \\
\text { vés das quais as } \\
\text { imagens podem } \\
\text { interagir com } \\
\text { textos verbais } \\
\text { para construir } \\
\text { sentidos (...) }\end{array}$ & AUSENTE \\
\hline
\end{tabular}

Quadro 04: Resultados parte 02 (Fonte: Desenvolvido a partir dos artigos selecionados) 
Na parte final, percebemos que não é atitude comum dos quatro artigos a avaliação da descoberta. Entretanto os autores expõem categoricamente a comparação da descoberta com a literatura. O resumo dos resultados e a conclusão também não são apresentados, com exceção do trabalho de Carvalho (2016) que destaca essas duas unidades entre dois parágrafos.

Acreditamos ser imperativo o desenvolvimento de pesquisas que tenham como foco a seção de discussão dos artigos, para que possam destacar as unidades retóricas e aperfeiçoar o desenvolvimento dos resultados das pesquisas.

Na subseção sequente, abordaremos as formas de compor retoricamente a conclusão dos artigos científicos.

\subsection{Discussão acerca da Conclusão}

Nesta subseção discutiremos acerca das unidades retóricas presentes nas conclusões dos quatro artigos selecionados para análise. Matta-Roth e Hendges (2010, p.131) explicam que é nessa etapa do artigo que comumente se faz "um breve sumário ou conclusão do que foi feito e a significação disso para a área".

Os trabalhos sobre lexicografia e multimodalidade de Duarte e Pontes (2013) e o de Fechine e Pontes (2011) apresentam apenas a parte que resume e interpreta os resultados obtidos no trabalho e a parte que apresenta clara e resumidamente as evidências para a conclusão. 
Hermont (2016) apresenta quase todas as unidades retóricas, com exceção da parte que demonstra como seus resultados e interpretações concordam ou contrastam com pesquisas prévias, oferecendo possíveis razões para os resultados obtidos. É importante destacar que o trabalho discute as implicações teóricas do trabalho, a validade $d a$ teoria ${ }^{4}$, bem como suas possíveis aplicações práticas:

Excerto 06:

A utilização do modelo GeM proposto por Bateman (2008) foi totalmente viável, contribuindo para que pudéssemos chegar à conclusão acerca dos níveis de multimodalidade (...) (HERMONT, 2016, p.735)

A citação evidencia quando o autor destaca acerca da relevância da teoria para a sua pesquisa, mostrando que a abordagem é viável para a proposta que segue.

Contudo, é na pesquisa de Carvalho (2016) que todas as unidades retóricas são contempladas de forma satisfatória, conforme poderemos observar na tabela a seguir:

4 Figueiredo-Gomes (2017). 


\section{SEÇÃO DE CONCLUSÃO DE ARTIGO ACADÊMICO}

CARVALHO, S. A. (2016). "Interações imagem-texto: uma análise de composições multimodais instrucionais". RBLA, Belo Horizonte, v. 16, n. 4, 547-573.

Resume e interpreta os resultados obtidos no trabalho (e não os recapitula);
Demonstra como seus resultados e interpesquisas prévias, oferecendo possíveis razões para os resultados obtidos; pretações concordam ou contrastam com

detectamos que o ambiente on-line apresenta

diversos modos interagindo entre si, às vezes em composições trimodais,

como foi o caso da composição imagem/texto/ vídeo, que apresentamos

na tabela de modos encontrados em interação com outros modos.

Outro aspecto a ser considerado é que, apesar de alguns estudos já terem sido realizados nessa área (ROTH; POZZER-ARDENGHI; HAN, 2005; UNSWORTH, 2006; UNSWORH; DALY, 2011), ela ainda carece de teorias que venham embasar análises como as que apresentamos neste

estudo.

Não é tímido(a); discute as implicações teóricas do trabalho, a validade da teoria ${ }^{1}$, bem como suas possíveis aplicações práticas;

Apresenta clara e resumidamente as evidências para a conclusão;

Recomenda futuros aprofundamentos das questões discutidas no trabalho, deixando aberta uma lacuna a ser preenchida por futuras pesquisas.
A teoria de análise dessas interações proposta por Martinec e Salway (2005) consegue dar conta, como metalinguagem, de explicar as relações que encontramos no material didático

Foram detectadas majoritariamente composições de imagem estática e texto verbal - treze ocorrências.

Em nossa busca por teorias que embasem análise de construção de sentido de forma multimodal, não identificamos teorias que permitissem uma análise, por exemplo, de interações entre modos tão diversos, como exemplo, vídeo, imagem e texto.

Quadro 05: Conclusão (Fonte: Desenvolvido a partir dos artigos selecionados)

Evidenciamos, com esses resultados, que três dos quatro artigos selecionados apresentam de forma insatisfatória as unidades retóricas propostas por Matta-Roth e Hendges (2010). 
O trabalho de Carvalho (2016) parece contemplar, de um modo geral, as unidades retóricas, seguindo um padrão de construção de um texto mais claro, objetivo e coeso.

Após a análise dos textos, para nós foi inesperado constatar que nem todos os artigos seguem o padrão das unidades retóricas, tendo em vista o nível do periódico no qual eles estão ancorados (RBLA, Qualis A e as demais com Qualis B).

Por fim, acreditamos que essa análise possa contribuir de forma positiva com as pesquisas que tratam sobre ensino de escrita, em especial ensino de escrita em uma cultura disciplinar, como é o caso do ensino do artigo científico no meio acadêmico.

\section{CONSIDERAÇÕES FINAIS}

Nosso artigo teve como objetivo descrever e interpretar as unidades retóricas que compõem a área disciplinar da Multimodalidade. Para a realização do objetivo, a pesquisa aqui empreendida explorou e descreveu as unidades retóricas das seções de quatro artigos acadêmicos, coletados em periódicos indexados pela CAPES, da cultura disciplinar da área da Multimodalidade.

O desenvolvimento da Introdução dos quatro artigos é bastante divergente entre si. Apenas um artigo apresenta maior número das unidades retóricas que compõe o modelo CARS (SWALES, 1990). O modelo de Figueiredo-Gomes (2017) apresenta cerca de $90 \%$ dos artigos na parte da revisão 
da literatura. A unidade da metodologia do modelo de Lim (2006) também é pouco explorado, com exceção de um artigo, que contempla a maior parte dos movimentos retóricos. A unidade de análise dos artigos é a maior parte na avaliação entre as unidades. Os autores elaboram a descrição e interpretação dos resultados e são explicados a partir de imagens e gráficos. Na seção retórica de conclusão, apenas um artigo constrói contemplando todos os movimentos do quadro proposto por Motta-Roth e Hendges (2010).

Acreditamos que a teoria adotada em nossa pesquisa atende de forma satisfatória os objetivos do nosso trabalho. Salientamos a necessidade de aprofundamento de pesquisas das unidades retóricas de artigos acadêmicos da área da Multimodalidade.

\section{REFERÊNCIAS}

BERNADINO, Cibele Gadelha (2007). O metadiscurso interpessoal em artigos acadêmicos: espaço de negociações e construção de posicionamentos. (Tese - Doutorado em Linguística Aplicada) - Universidade Federal de Minas Gerais, Belo Horizonte.

CARVALHO, Sâmia Alves (2016). "Interações imagem-texto: uma análise de composições multimodais instrucionais". RBLA, Belo Horizonte, 16(4), 547573.

COSTA, Raquel Leite Saboia da (2015). Culturas disciplinares e artigos acadêmicos experimentais: um estudo comparativo da descrição sociorretórica. (Dissertação - Mestrado Acadêmico) - Universidade Estadual do Ceará, Fortaleza.

DUARTE, Eduarda; PONTES, Antônio (2013). “A metafunção composicional nas páginas do dicionário on-line Merriam-Webster". Revista E-scrita. 4, 51-68. 
FECHINE, Lorena Américo Ribeiro; PONTES, Antônio Luciano (2011). "A construção verbal e visual dos verbetes de um dicionário monolíngue básico em língua inglesa". ReVEL, 9(17).

FIGUEIREDO-GOMES, João Bosco et al (2017a). Padrões de complexidade textual: uma proposta funcionalista para avaliação de desempenho de alunos do ensino médio. 10 Relatório apresentado ao CESPE/CEBRASPE. Brasília: CESPE/CEBRASPE.

HERMONT, Thiago Brazileiro Vilar (2016). “Uma análise multimodal à luz do modelo GeM: homepage do Ministério do Meio Ambiente do Brasil". RBLA, Belo Horizonte, 16(4), 709-743.

HYLAND, Ken (1996). "Writing without conviction? Hedging in science research articles". Applied Linguistics. 17(04), 433-454.

(2000). Disciplinary discourse: social interactions in academic writing. Singapura: Pearson Edacation Limited.

MOTTA-ROTH, Desiree; HENDGES, Graciela. Rabuske (2010). Produção textual na universidade. São Paulo: Parábola Editorial.

PACHECO, Jorge Tércio Soares (2016). O artigo acadêmico na cultura disciplinar da área de Nutrição: uma investigação sociorretórica. (Dissertação - Mestrado em Linguística Aplicada) - Programa de Pós-Graduação em Linguística Aplicada, Universidade Estadual do Ceará, Fortaleza.

SWALES, John (1990). Genre analysis: English in academic and research settings. Cambridge: University Press.

(2004). Research genres: explorations and applications. Cambridge:

Cambridge University Press.

Aluizio Lendl é Doutorando em Letras pela Universidade do Estado do Rio Grande do Norte (UERN), Brasil. Sob a linha de pesquisa dos estudos do "Texto e construção dos sentidos". 